\title{
Behaviour of underpinning piles due to shield tunnel installation
}

\section{Bolin Wang}

Lecturer, Department of Geotechnical and Underground Engineering, School of Civil Engineering, Lanzhou Jiaotong University, Lanzhou, China (corresponding author: wang-bo-lin@163.com) (Orcid:0000-0003-4939-5050)

\author{
Xu Wang \\ Professor, Department of Geotechnical and Underground Engineering, \\ School of Civil Engineering, Lanzhou Jiaotong University, Lanzhou, China \\ (Orcid:0000-0003-4678-1570) \\ Wenjie Ma \\ Postgraduate, Department of Geotechnical and Underground Engineering, \\ School of Civil Engineering, Lanzhou Jiaotong University, Lanzhou, China \\ (Orcid:0000-0003-2819-8680)
}

A laboratory simulation of the number 1 metro line in Lanzhou City, China, was carried out to determine the feasibility of passing through existing bridge projects. The results show that the foundation settlement of the underpinning piles is less than that of the existing piles. A great change in the axial forces on underpinning piles occurs about $10 \mathrm{~cm}$ lower than it does on the existing piles. The side friction of the underpinning piles reaches

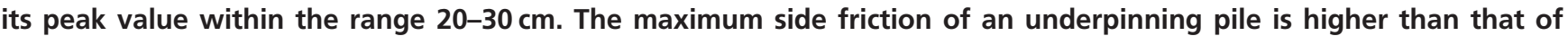
the existing piles. The bearing capacity of the underpinning pile system is larger than that of the existing pile system. In the excavation simulation of a shield tunnel, the axial forces on underpinning piles change in a similar manner as that of the existing piles at excavation depths of $0-20$ and $100-120 \mathrm{~cm}$. Negative friction occurs when the depth of excavation is $30 \mathrm{~cm}$, and it reaches a maximum at $20 \mathrm{~cm}$ from the tops of the underpinning piles. The neutral point is about $32 \mathrm{~cm}$ from the top of the pile body. The load-sharing ratio of the pile cap increases with increases in loading.

\section{Notation \\ $C_{E} \quad$ similarity coefficient of the elasticity modulus \\ $C_{G} \quad$ similarity coefficient of the shear modulus \\ $C_{k} \quad$ rigidity similarity coefficient \\ $C_{l} \quad$ similarity coefficient of length \\ $C_{M} \quad$ similarity coefficient of the bending moment \\ $C_{P} \quad$ similarity coefficient of pressure \\ $C_{u} \quad$ similarity coefficient of the vertical displacement \\ $C_{\gamma} \quad$ similarity coefficient of shear strain \\ $C_{\varepsilon} \quad$ similarity coefficient of normal strain \\ $C_{\mu} \quad$ similarity coefficient of Poisson's ratio \\ $C_{\sigma} \quad$ similarity coefficient of normal stress \\ $C_{\tau} \quad$ similarity coefficient of shear strength \\ L length}

\section{Introduction}

Subway construction has become increasingly prevalent in urban areas to relieve urban traffic congestion. The continuous development of subway networks imposes higher requirements on the construction environment. This is often carried out by intersecting new and old lines, as well as passing them through existing buildings (Iwasaki et al., 1994; Takahashi et al., 2004; Yamaguchi et al., 1998). In the construction of urban railway systems, the stress of the pile-foundation underpinning structure system is relatively clear, and this can solve the settlement problem of existing buildings caused by tunnel excavation. Such foundations have been widely used in urban railway systems in major cities, such as Beijing, Shanghai, Shenzhen and Nanjing in China (Liu et al., 2014; Mao et al., 2012; Yang et al., 2006).
Pile-foundation underpinning is mainly employed in the foundations of houses built in loess areas, such as Lanzhou, Xi' an and Xining. This is due to the high porosity of loess structures, which results in soil settlement, landslides and roadbed erosion by water (Huang and Huang, 2013). However, there are few theoretical or experimental studies on pilefoundation underpinning in loess regions. Liu et al. (2005) provided technological references for the application of preloaded pile underpinning in saturated loess regions based on the rectification of a residential building in Xi'an City. Tong (1989) discussed the applications of pile-foundation underpinning technology in industrial and civil buildings built on wet collapsible loess. Using the midas GTS software, Wu (2016) and Cui (2016) carried out a finite numerical simulation of the pilefoundation underpinning technology used in a subway tunnel in Lanzhou City that was constructed in saturated loess sediment.

In this research, the Lanzhou subway, to be constructed under the existing pile foundation of Yuergou Bridge, was studied. A shield tunnel passing through the pile foundation under a bridge in a loess region was studied through laboratory model testing. Changes in pile-foundation settlement, the axial forces of the pile body and the side friction of piles before and after the truncation of the existing piles were investigated. The conclusions provide a theoretical reference for the construction and design of underpinning piles. The model testing was carried out in a test tank at the Rock Test Hall of Lanzhou Jiaotong University. A similar ratio of loess and soil to that found at construction sites was used to measure the physical mechanical parameters of 
loess. In this way, the research conclusions may guide similar engineering practices in the future.

\section{Experimental section}

\section{Similarity of model test}

Testing models and prototypes must meet physical, geometric and boundary similarities to make the results applicable to practical engineering. The physical similarity has to meet

1. $C_{\mu}=1 \quad C_{\varepsilon}=C_{\gamma}=1 \quad C_{\sigma}=C_{E}=1 \quad C_{\tau}=C_{G}$

where $C_{\mu}, C_{\varepsilon}, C_{\gamma}, C_{\tau}, C_{\sigma}, C_{E}$ and $C_{G}$ are the similarity coefficients of Poisson's ratio, normal strain, shear strain, shear strength, normal stress, elasticity modulus and shear modulus.

The geometric similarity must meet

2. $\frac{C_{u}}{C_{\varepsilon} C_{l}}=1$

where $C_{u}$ and $C_{l}$ are the similarity coefficients of vertical displacement and length, respectively.

The rigidity similarity must meet

3. $\frac{C_{E} C_{l}}{C_{k}}=1 \quad \frac{C_{G} C_{l}}{C_{k}}=1$

where $C_{k}$ is the rigidity similarity coefficient.

The similarity of boundary conditions refers to the similarity among boundary constraints, stress and supporting conditions. Based on knowledge of elastic mechanics, the boundary similarity between the model and prototype can be represented by

4. $C_{P}=C_{\sigma} C_{l}^{2} \quad C_{M}=C_{\sigma} C_{l}^{3}$

Therefore, the geometric similarity ratio of the model is finally determined as 1:23. The rest of the physical parameters can be deduced in the same way.

\section{Manufacturing of model piles}

Square aluminium tubing with a $15 \times 15 \mathrm{~mm}$ cross-section was used for the model piles. Strain gauges were installed symmetrically on the two sides of the aluminium tube (Figure 1). The outer surface of the model pile was formed by C30 fine concrete (standard compressive strength of $30 \mathrm{MPa}$ ). All model piles were cured to $28 \mathrm{~d}$ after manufacturing. The model piles were made in two lengths. Specifically, the model piles used to simulate the existing piles and underpinning piles were 0.8 and $0.6 \mathrm{~m}$ long,

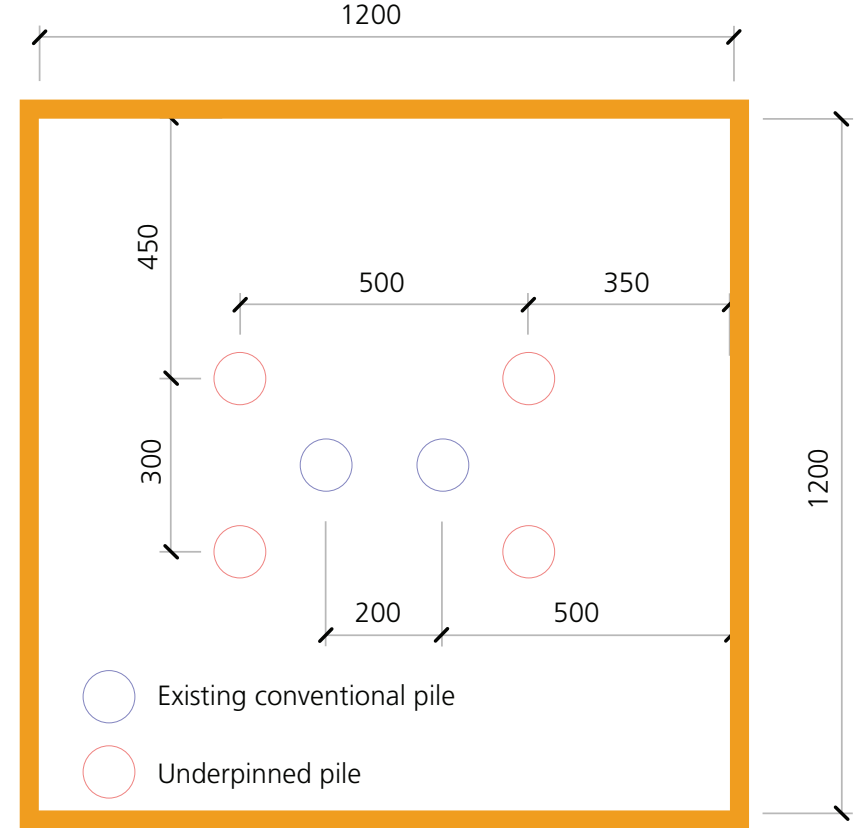

Figure 1. Positions of strain gauges (dimensions in millimetres)

respectively. The diameter of all piles was the same $(60 \mathrm{~mm})$. In this experiment, a total of six piles were used, including two for simulating the existing piles and four for simulating the underpinning piles. Here, the axial forces and side friction of the model piles were mainly measured by strain gauges. Hence, the accuracy and rating curves of the strain gauges are key points in the experiment. The same batch of strain gauges (BX120-10AA resistance strain gauges, made in Guangzhou, China) was calibrated before the experiment. The grid size was set to $3 \mathrm{~mm}$ (length) $\times$ $2 \mathrm{~mm}$ (width). The resistance and sensitivity coefficients were $120 \pm 2$ and $2 \cdot 19 \pm 1 \%$, respectively. Special pile caps were manufactured at the top of the piles, on which sensors were installed. Pressure sensors were buried at the ends of the piles to measure the loads at the top and end of the piles.

\section{Experimental apparatus}

The dimensions of the test tank used in the laboratory model experiment were $1.2 \mathrm{~m} \times 1.2 \mathrm{~m} \times 1.2 \mathrm{~m}$. Organic glasses on three surfaces were fixed by angle irons. One surface was an assembly of an angle iron and a wooden plate. The model test was accomplished under two working conditions. In working condition 1 , only the existing piles were buried in the test tank and the piles were tested in static conditions to track the entire load-displacement curve up to failure. The axial force and ultimate bearing capacity of the existing piles were tested. In working condition 2, both the existing piles and underpinning piles were buried in the test tank for convenience in carrying out the experimental study. Loads were increased to one-half of the ultimate bearing capacity of the original pile under working condition 1 and then kept constant. In the same time, a rigid cap was made by pouring reinforced concrete into the upper portion of the underpinning piles. The cap height, length and width were set as 10 , 
60 and $40 \mathrm{~cm}$, respectively. Piles were cut from the middle at $50 \mathrm{~cm}$ above the bottom of the test tank after the loads were kept stable. Meanwhile, a shield tunnel with an excavation diameter of $25 \mathrm{~cm}$ was simulated. A hole was made on the wooden plate of the test tank, and soils were pulled out through this hole by a Luoyang shovel. Poly(vinyl chloride) (PVC) plastic tubes were used to support the processing of excavation (the positions surrounding the PVC tubes were wrapped with reinforcing mesh and then filled with cement slurry). Loads above the underpinning pile system were increased to 2.4 times the ultimate bearing capacity of working condition 1 after the underpinning system was stable. The plane layout of the test tank is shown in Figure 2. The vertical layout and excavation position of the tunnel are shown in Figure 3. The loading

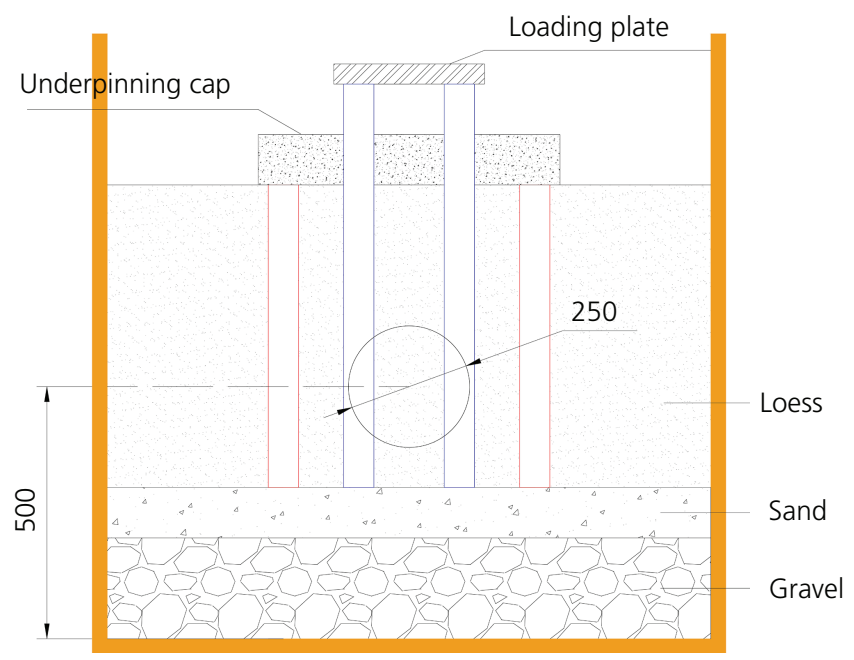

Figure 2. Plane layout of the model (dimensions in millimetres)
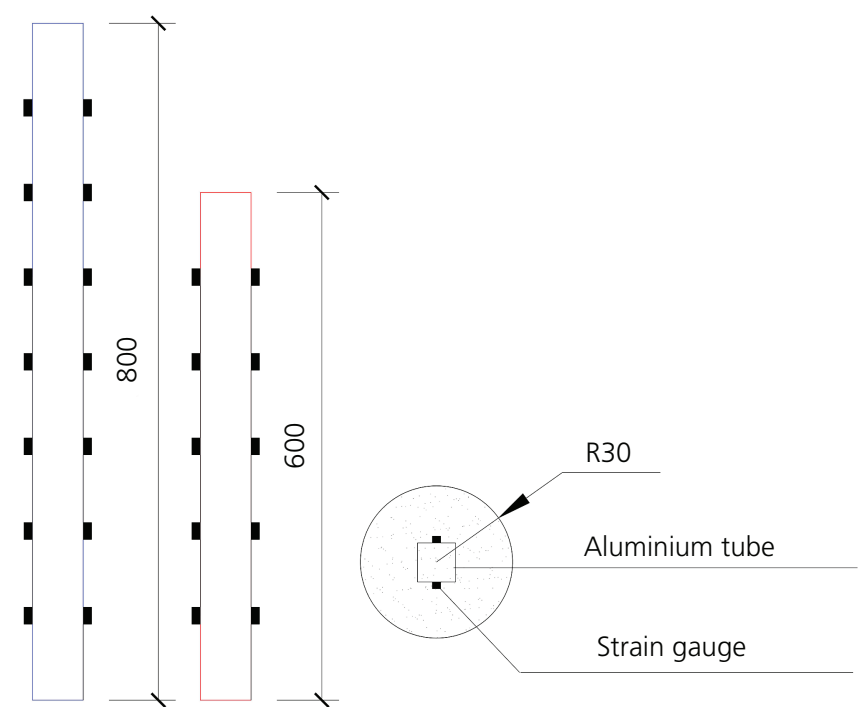

Figure 3. Vertical layout of the model (dimensions in millimetres) process was accomplished at a low speed. The ultimate bearing capacity of a single original pile was estimated as $6.82 \mathrm{kN}$ according to the relevant calculation method. A total of nine loading levels were performed. Loads of $1.5 \mathrm{kN}$ were applied to the existing piles at each level except for a $3 \mathrm{kN}$ load at the first level, while $3 \mathrm{kN}$ loads were applied to the underpinning piles at each level. The loading failure was determined according to the technical specification for building pile testing (MHURD, 2014). In this experiment, if settlement under a certain loading reached twice that of the previous loading level and settlement did not achieve relative stability within $1 \mathrm{~h}$, the test was deemed a failure. Dial indicators were placed on the loading plate and at the four corners of the cap to measure settlement before and after pile-foundation underpinning. The loading device after cap pouring is shown in Figure 4.

\section{Filling of the test tank}

The loess used to fill the test tank was disturbed soil from different layers of the Yuergou Bridge construction site. Loess samples were brought back to the laboratory for soil testing, through which physical mechanical parameters were gained (Table 1).

The test tank was filled and compacted layer by layer. Level scales were pasted on the four inner walls of the test tank to measure the filling thickness and compaction thickness. The thickness of each soil layer was controlled to about $15 \mathrm{~cm}$. The compaction degree of the filled soil was consistent with that of a site, which reached $90 \%$. A $20 \mathrm{~cm}$ thick layer of gravel and a $10 \mathrm{~cm}$ thick layer of sand were poured into the bottom of the test tank to form a soil-supporting layer.

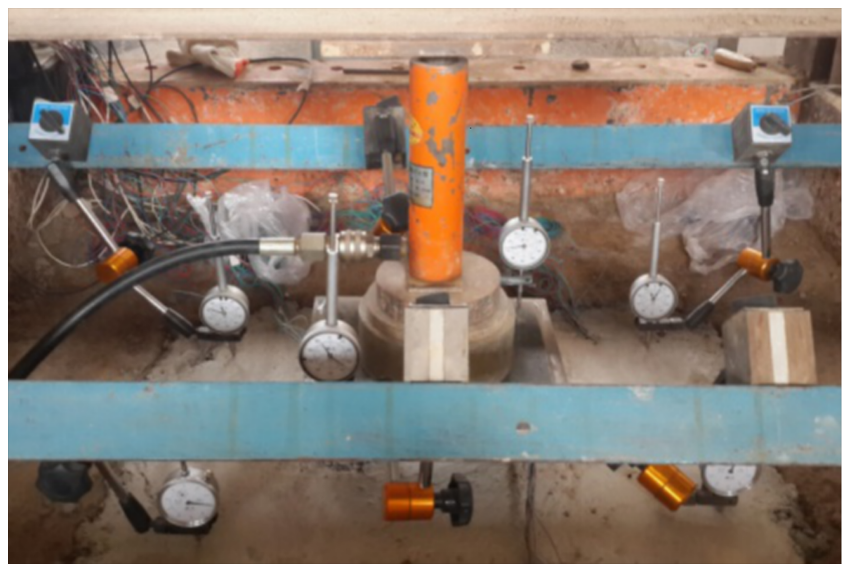

Figure 4. Photograph of the loading test device

Table 1. Physical parameters of the loess used in this study

\begin{tabular}{lcccc}
$\begin{array}{l}\text { Specific } \\
\text { gravity: } \\
\mathbf{g} / \mathbf{c m}^{3}\end{array}$ & $\begin{array}{c}\text { Optimum } \\
\text { moisture } \\
\text { content: } \%\end{array}$ & $\begin{array}{c}\text { Maximum dry } \\
\text { density: } \\
\mathbf{g} / \mathbf{c m}^{3}\end{array}$ & $\begin{array}{c}\text { Liquid } \\
\text { limit: } \\
\%\end{array}$ & $\begin{array}{c}\text { Plastic } \\
\text { limit: } \\
\%\end{array}$ \\
\hline 2.69 & 16.8 & 1.78 & 33.2 & 19.0 \\
\hline
\end{tabular}


Behaviour of underpinning piles due to

shield tunnel installation

Wang, Wang and Ma

\section{Analysis of experimental results}

Load-settlement curve

The load-settlement curve obtained from static loading testing provides an empirical judgement of the ultimate bearing capacity of piles. Moreover, it can comprehensively reflect the axial force and side friction of the piles.

The load-settlement curves are shown in Figure 5. A linear relationship between settlement and load was observed when the loads at the top of the existing piles increased from 3 to $12 \mathrm{kN}$. They indicate that elastic deformation developed at the ends and sides of the existing piles during initial loading. A turning point is evident on the load-settlement curves at $13.5 \mathrm{kN}$, manifested as dramatic changes in settlement. The average settlement change at each loading level was about $1 \mathrm{~mm}$ below $13.5 \mathrm{kN}$, while it was $3.81 \mathrm{~mm}$ between 13.5 and $15 \mathrm{kN}$, indicating that the soil mass tended towards failure at this loading level. The settlement of the piles increased significantly when the loading increased to $15 \mathrm{kN}$, which reflects the yield of the soil mass. The side friction and tip resistance of the piles both reached their maximum values, and punching failure of the piles developed. Therefore, the ultimate bearing capacity of the existing piles was considered to be $13.5 \mathrm{kN}$. Due to the existence of caps, the load-settlement curve of the underpinning piles changed slightly when the load on the upper position of the cap increased from 3 to $33 \mathrm{kN}$. No significant turning point was observed on the curve. Given the same loads, the settlement of the underpinning piles was significantly less than that of the existing piles. For instance, the settlements of the underpinning piles at 6,9 and $12 \mathrm{kN}$ were $42 \cdot 2$, $37 \cdot 2$ and $29 \cdot 5 \%$ of those for the existing piles, respectively.

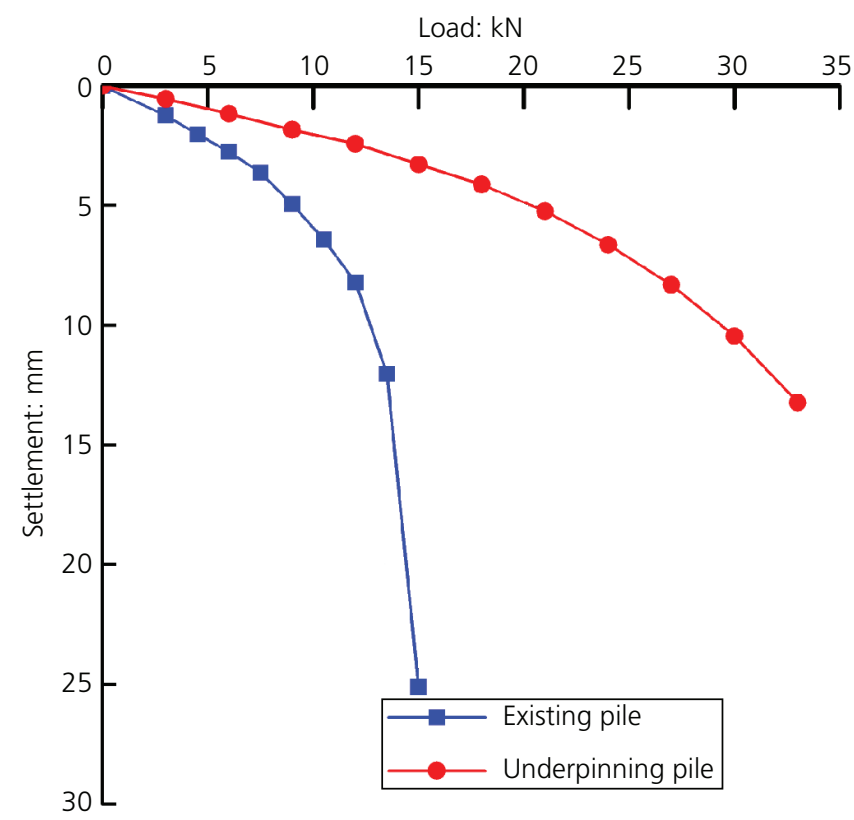

Figure 5. Load-settlement curves of the existing pile and underpinning pile

\section{Axial force of piles}

Considering the symmetrical arrangement of the piles, one original pile and one underpinning pile were randomly selected for analysis. In Figures 6 and 7, the axial forces on both original and underpinning piles changed in a basically consistent manner under different loading levels. The axial forces on original and underpinning piles decreased continuously from top to bottom. The pile tip resistance developed gradually with increases in the loading level, reaching $2 \cdot 41$ and $2.64 \mathrm{kN}$ at 15 and $33 \mathrm{kN}$, respectively.

It can be seen from Figure 6 that the axial forces on the existing piles changed drastically between 10 and $20 \mathrm{~cm}$, indicating the

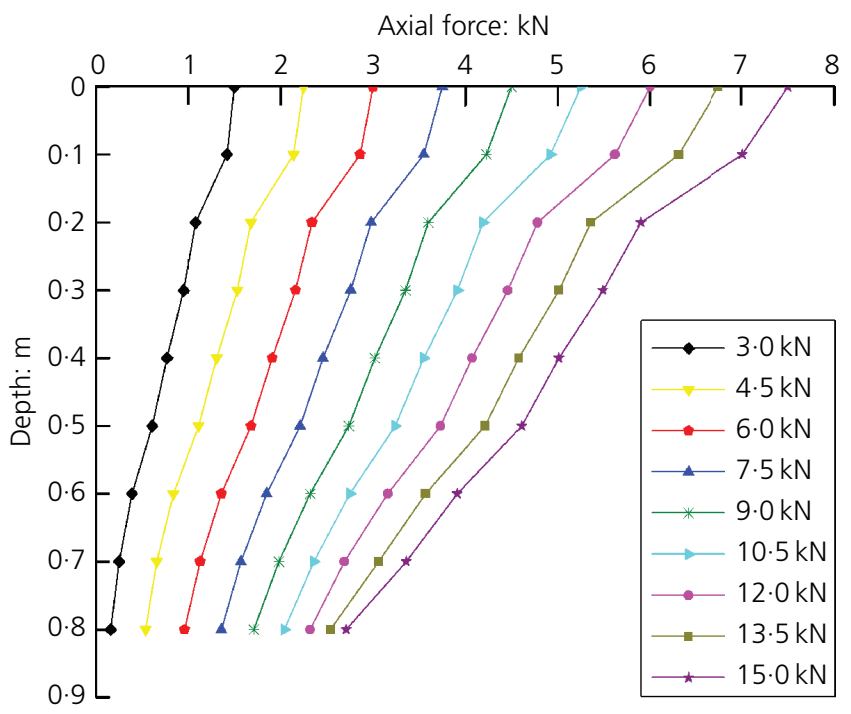

Figure 6. Axial forces on the existing piles

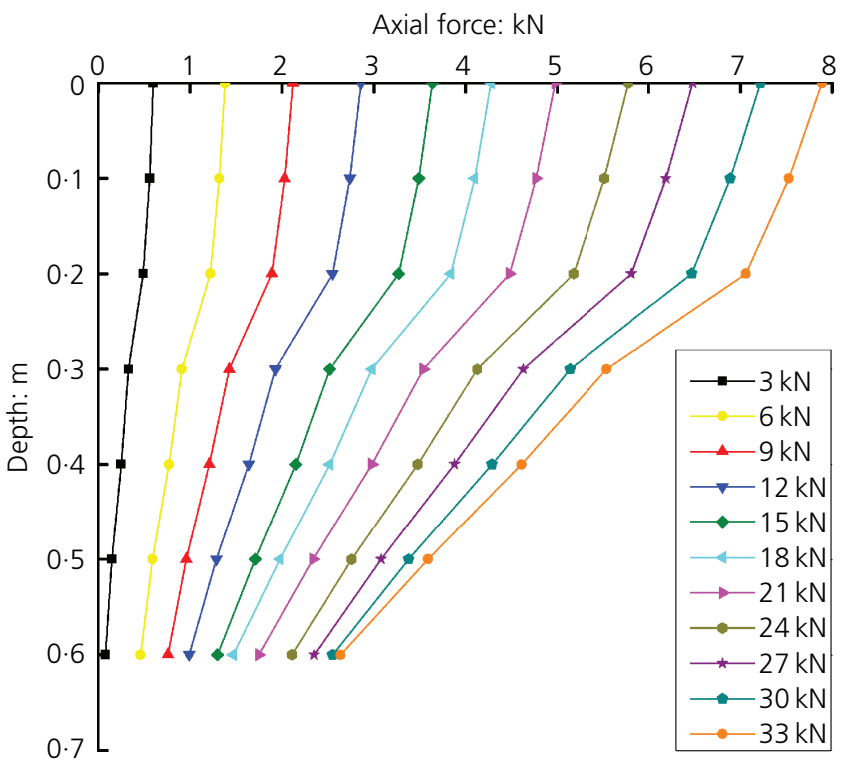

Figure 7. Axial forces on the underpinning piles 
full development of side friction on the piles and large pile-soil relative displacement at this point. The axial force at the pile end dropped significantly at $15 \mathrm{kN}$, which indicates punching failure at the pile end. At the same time, the pile body reached the ultimate bearing state. Figure 7 shows that the cap restricted the pile-soil relative displacement at an excavation depth of less than $30 \mathrm{~cm}$. Consequently, development of side friction on the piles below the cap was confined. The axial forces on piles attenuated significantly at excavation depths of $20-30 \mathrm{~cm}$. The position of the greatest axial force on the underpinning piles changed at a position about $10 \mathrm{~cm}$ lower than that on the existing piles.

The relationship between the axial forces on underpinning piles and excavation depth $(0-20 \mathrm{~cm})$ is similar to that of the existing piles (Figure 8). Settlement of upper soils in the tunnel is quicker than settlement of underpinning piles in the advancing process. Hence, negative friction is produced on piles. Axial forces above $30 \mathrm{~cm}(50 \%$ of the pile length (PL), or $0.5 \mathrm{PL})$ on piles increase when the excavation depth increases from 30 to $90 \mathrm{~cm}$. The maximum axial force is reached at $30 \mathrm{~cm}$ from the top of the underpinning piles. According to the concept of the neutral point, the position of the peak axial force is equal to the position of the neutral point. In other words, there is no pile-soil relative displacement at $0 \cdot 5 \mathrm{PL}$ of piles. Axial forces below $30 \mathrm{~cm}(0 \cdot 5 \mathrm{PL})$ of the piles are negatively related to excavation depth. The changes in the axial forces on the underpinning piles are similar to those on the existing piles when the reversed excavation depth is $0-20 \mathrm{~cm}(100-120 \mathrm{~cm})$.

Comparisons of the axial forces on the original and underpinning piles under the same loads are shown in Figure 9.

In Figure 9, the axial force on the existing piles is significantly stronger than that on the underpinning piles given the same loading level. This runs counter to engineering practices. At construction sites, the axial force on the existing piles is small in some cases, which is attributed to the large total dead loads on the

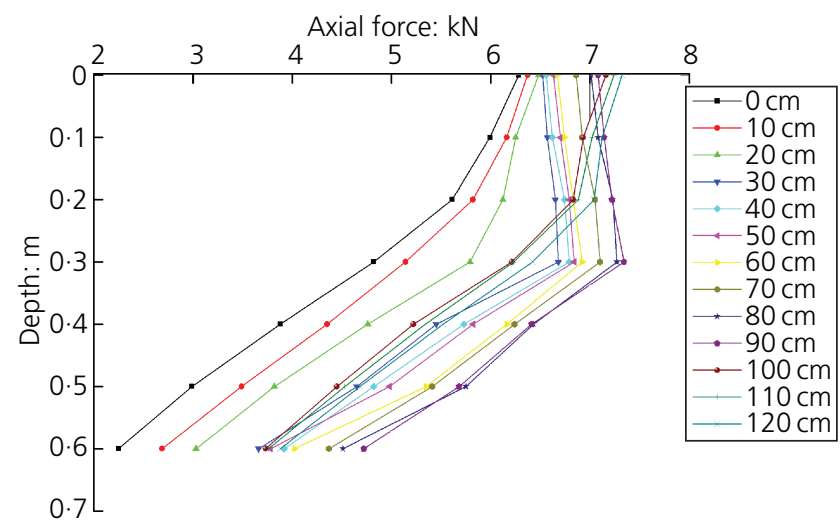

Figure 8. Axial forces on the underpinning piles under different excavation depths caps and foundations of underpinning piles. Based on this laboratory model test, the underpinning pile system conforms better to engineering requirements. The axial force difference between the original and underpinning piles is greater with increases in the loads at the tops of the piles. For example, the ratios between such axial force differences and total loads are $2 \cdot 67,8 \cdot 33,10 \cdot 56,11 \cdot 48$ and $12 \cdot 60 \%$ when the loads at the tops of the piles are $3,6,9,12$ and $15 \mathrm{kN}$, respectively. This demonstrates that the caps of underpinning piles share a great proportion of the load in the underpinning system. As the loading process continues, the shearing ratio increases and the bearing capacity of the underpinning system increases accordingly.

\section{Side friction of piles}

The side friction on the existing piles and underpinning piles is shown in Figures 10 and 11, respectively.

Figures 10 and 11 reveal that side friction on the piles develops gradually with increases in the vertical loads. The side friction distributions on the existing piles and underpinning piles are basically consistent. The overall compressive deformation of the middle soil mass is the major failure mode, which is caused by caps and displacement coordination at the tops of the piles. Therefore, the pile-soil relative displacement is smaller than the upper and lower displacements of the piles.

The side friction on the existing piles reaches a maximum at about $20 \mathrm{~cm}(0 \cdot 25 \mathrm{~L})$. This reveals that maximum pile-soil relative displacement occurs in this section. Later, the pile-soil relative displacement decreases with increases in excavation depth, and another peak occurs close to $60 \mathrm{~cm}(0 \cdot 75 \mathrm{PL})$. Unlike the existing piles, the underpinning piles achieve maximum side friction at a deeper position (about $30 \mathrm{~cm}(0 \cdot 5 \mathrm{PL})$ ). Due to the pile-soil collaborative settlement within a certain range below the poured cap, the pile-soil relative displacement is small and the side frictions at both ends of the existing piles and underpinning piles converge.

It can be seen from Figure 12 that, when the excavation depth is within the ranges $0-20$ and $100-120 \mathrm{~cm}$, the pile foundation develops, or will develop, a downward displacement, since the soil settlement around the piles was less than the pile settlement. Hence, there is an upward applied force on the pile body, which is known as a positive friction force (Nie and Leng, 2013; Zhu et al., 2013). Due to the increasing pile-soil relative displacement above $30 \mathrm{~cm}(0.5 \mathrm{PL}$, or midpoint $)$ of the piles, the side friction increases gradually, while the side friction below $30 \mathrm{~cm}$ ( $0 \cdot 5 \mathrm{PL})$ decreases continuously. Another peak of side friction is observed at $50 \mathrm{~cm}(0 \cdot 83 \mathrm{PL})$. When the excavation depth is in the $30-90 \mathrm{~cm}$ range, the displacement of soil mass surrounding the piles is greater than the displacement of the piles due to excessive soil disturbance, which causes a downward dragging force. Hence, the side surfaces of the piles bear a downward-acting force, which is recognised as negative friction. Such negative friction may overlap the upper structural loads to offset partial positive friction, 


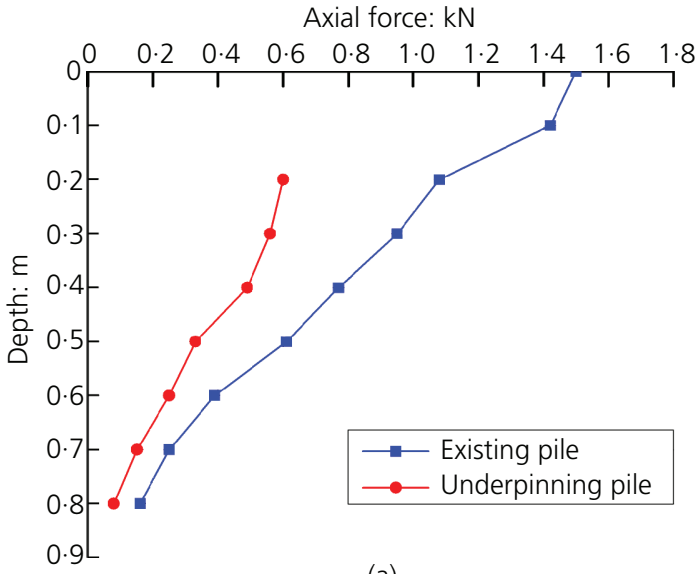

(a)

Axial force: $\mathrm{kN}$

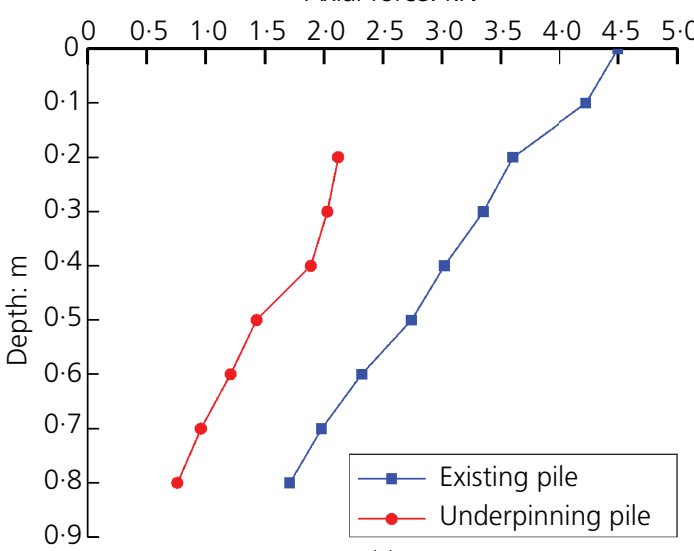

(c)

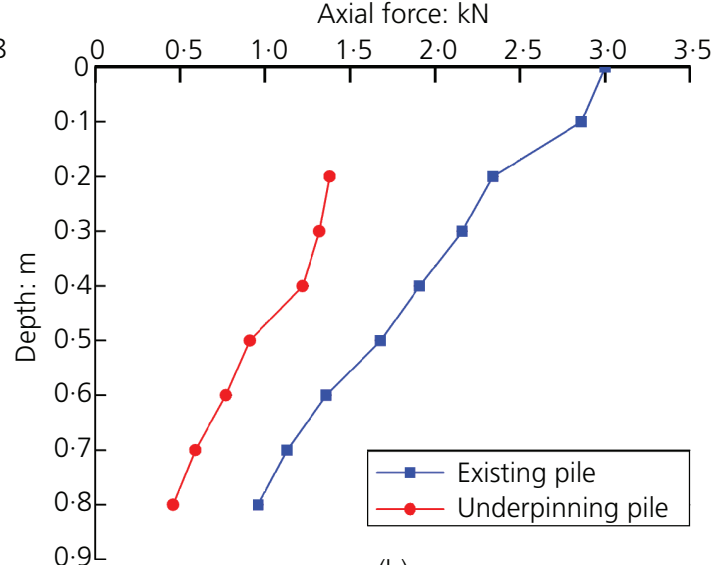

(b)

Axial force: $\mathrm{kN}$

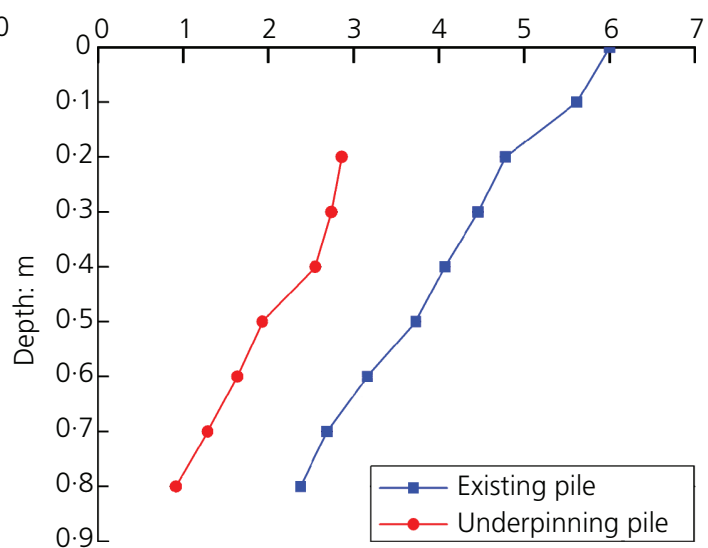

(d)

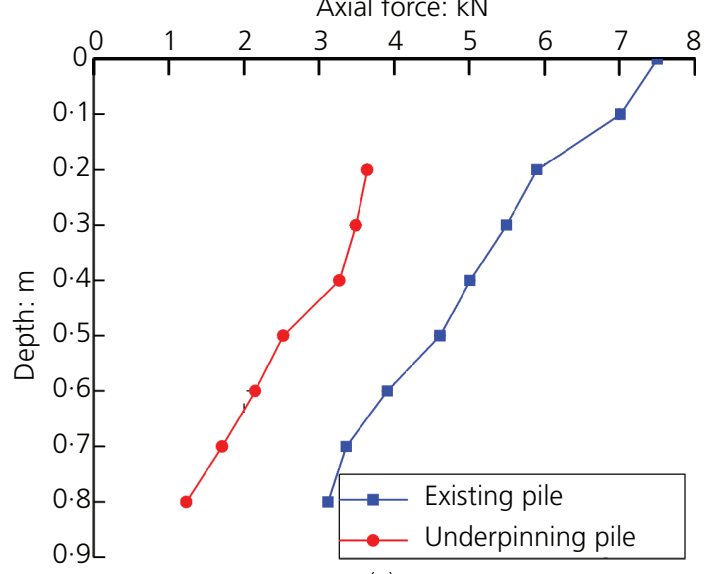

(e)

Figure 9. Comparisons of the axial forces on the existing piles and underpinning piles under loadings of (a) 3, (b) 6, (c) 9 , (d) 12 and (e) 15 kN

thus leading to increased settlement of the pile foundation and thereby influencing the normal service of the upper structure. When the excavation depth is in the range $30-90 \mathrm{~cm}$, the negative friction at the pile side reaches a maximum $(7.98 \mathrm{kPa})$ at $20 \mathrm{~cm}$ $(0 \cdot 33 \mathrm{PL})$ and the positive friction at the pile side reaches a peak at $40 \mathrm{~cm}(0 \cdot 67 L)$. The neutral point is at about $32 \mathrm{~cm}(0 \cdot 53 \mathrm{PL})$, where the pile-soil relative displacement is zero. Side friction decreases gradually below the neutral point.
Sharing of loads by the underpinning pile caps

Based on the preceding analysis of the axial forces on piles, the sum of the axial forces at the top of the underpinning piles is not equal to the total applied load. After the upper loads are applied, the caps of the underpinning piles share partial loads, which are transmitted downwards successively. The relationship between the load-sharing ratio of the caps and loading is shown in Figure 13. 


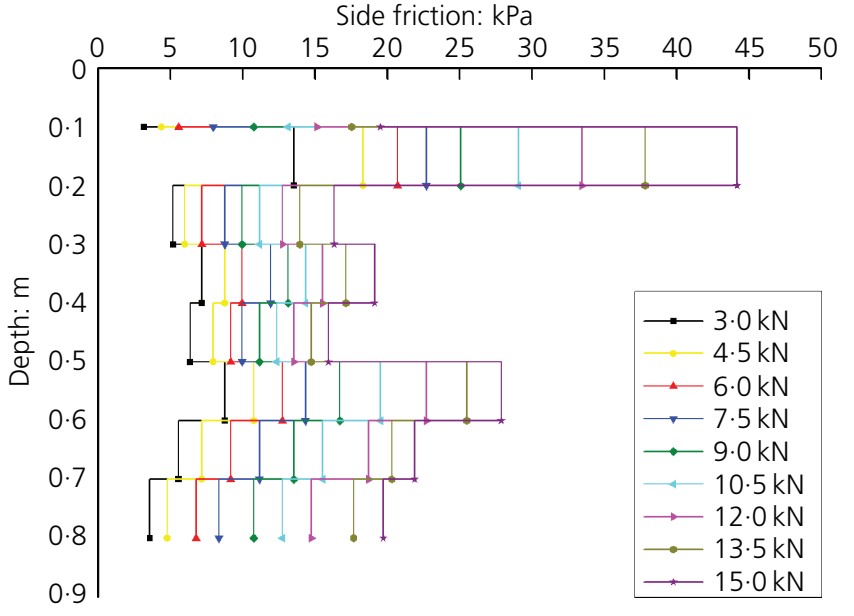

Figure 10. Side friction on the existing piles

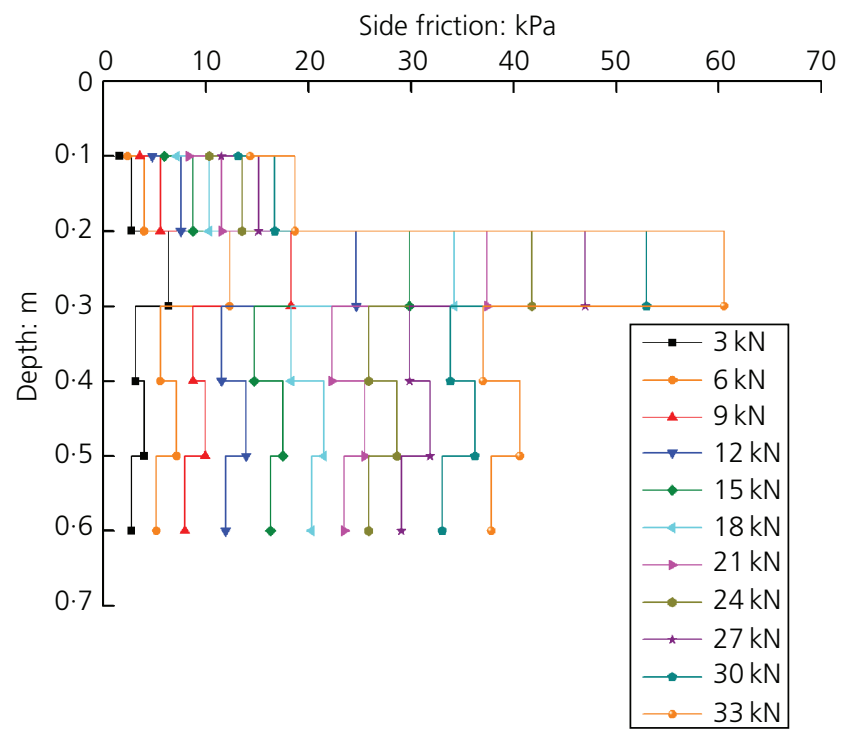

Figure 11. Side friction on the underpinning piles

In Figure 13, the load-sharing ratio of the pile caps is positively related to the load. The load-sharing ratio is $15 \cdot 12 \%$ at $3 \mathrm{kN}$, and the load is mainly borne by the piles. The load-sharing ratio of the pile caps is positively related to the applied loads at the top of the piles, which is attributed to the significantly higher rigidity of the pile caps than that of the soil mass. The load-sharing ratio of the pile cap is $22 \cdot 34 \%$ at $33 \mathrm{kN}$. This suggests that the pile cap shares more load under larger applied loads.

\section{Summary and conclusions}

The relationships between pile-foundation settlement, axial forces and side friction before and after pile-foundation underpinning were investigated through laboratory model testing. The following conclusions can be drawn.

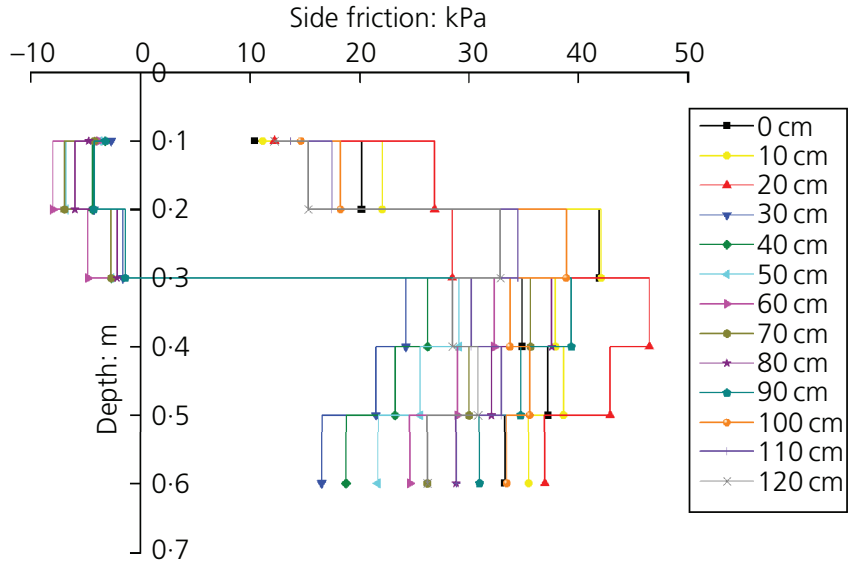

Figure 12. Side friction on an underpinning pile under different excavation depths

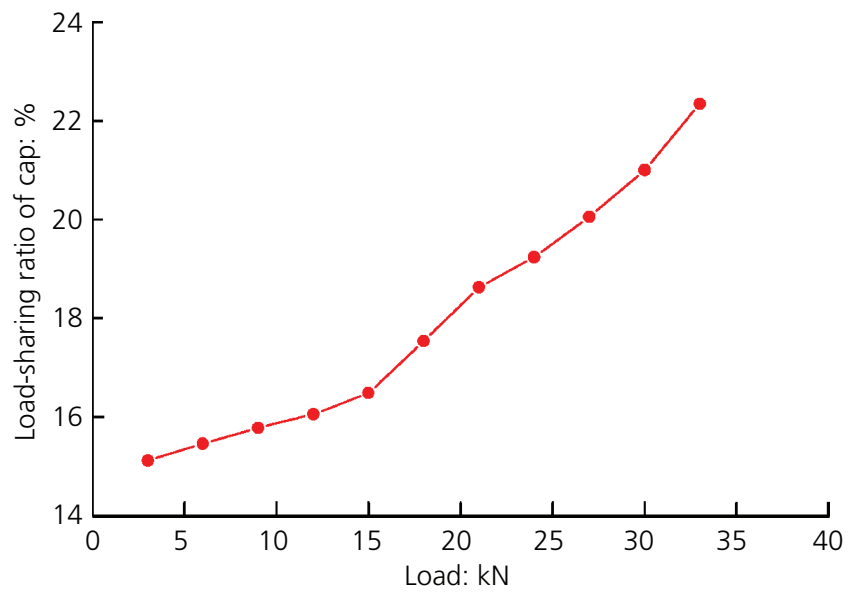

Figure 13. Changes in the load-sharing ratio of the cap under various loads

- The load-settlement curve of pile foundation in loess soil has a small slope in the early loading stage because side friction predominates. With continuous increases in loading, side friction develops thoroughly and the pile body fails gradually. The load-settlement curve of the existing piles generally presents a linear relationship as loads increase from 3 to $12 \mathrm{kN}$. A turning point is evident at $13.5 \mathrm{kN}$, indicating that the soil mass has yielded and the pile body has not failed. The overall settlement of the underpinning piles is smaller than that of the existing piles, which is caused by the pile cap.

- The relationship between the axial forces on piles in loess soil and excavation depth can be represented by a decreasing convex curve. The rate of change in axial force changes with increases in excavation depth. The pile-soil relative displacement at $30 \mathrm{~cm}$ below the pile cap is relatively small, 
resulting in slight changes in axial force. The position where drastic changes in axial force occur on underpinning piles is about $10 \mathrm{~cm}$ lower than that for the existing piles. Side friction reaches a peak at $30-50 \mathrm{~cm}$ from the top of the underpinning piles with increases in vertical loads. This peak is higher than the maximum side friction on the existing piles. The side friction close to the pile end converges gradually.

- In the excavation simulation of a shield tunnel, settlement of the soil mass surrounding the piles is less than the pile settlement at excavation depths of $0-20$ and $100-120 \mathrm{~cm}$. There is positive side friction, which has a relationship similar to that of the existing piles. Negative friction occurs when the excavation depth is $30 \mathrm{~cm}$ and reaches a maximum at $0.33 \mathrm{PL}$ of the pile body. The positive friction reaches a peak at $0 \cdot 67 \mathrm{~L}$ of the pile body. The neutral point is at about $0.53 \mathrm{PL}$ of the pile body. Side friction below the neutral point decreases gradually.

v The load-sharing ratio of the pile caps is positively related to the load. The bearing capacity of the surrounding soil mass of the piles develops thoroughly under the combined action of the piles, caps and soil masses. As a result, the bearing capacity of the pile foundation is increased.

\section{Acknowledgement}

The financial support from the National Natural Science Foundation of China (grant numbers 41662017 and 51469012) is gratefully acknowledged.

\section{REFERENCES}

Cui AH (2016) Application of passive bridge pile base underpinning technology in Lanzhou Metro. Railway Building 2: 76-79, https://doi. org/10.3969/j.issn.1003-1995.2016.02.19 (in Chinese).

Huang XD and Huang DC (2013) Design of active pile foundation underpinning project for Nanjing Metro Line 3. Urban Road Bridge and Flood Control 3: 92-94, https://doi.org/10.3969/j.issn.1009-7716. 2013.03.026 (in Chinese).

Iwasaki Y, Watanabe H and Fukuda M (1994) Construction control for underpinning piles and their behavior during excavation. Géotechnique 44(4): 681-689, https://doi.org/10.1680/geot.1994.44.4.681.
Liu LP, Li XY and Wang DW (2005) Practice of preloading underpinning pile reinforcement and uplift correction engineering. Journal of Rock Mechanics and Engineering 24(15): 2795-2801, https://doi.org/10. 3321/j.issn:1000-6915.2005.15.032.

Liu H, Xu SD and Zhou K (2014) Study on pile foundation replacement construction technology of Chuang-Ye Subway overpass. Journal of Shi Zia Zhuang Railway University (Natural Science Edition) 27(2): 23-26, https://doi.org/10.13319/j.cnki.sjztddxxbzrb.2014.02.05 (in Chinese).

Mao XF, Xu ZY and Hu JT (2012) Pile foundation underpinning design of Guangzhou-Shenzhen Railway Bridge on Shenzhen Metro Line 3. Journal of Railway Engineering Society 3: 91-95, https://doi.org/10. 3969/j.issn.1006-2106.2012.03.019 (in Chinese).

MHURD (Ministry of Housing and Urban and Rural Development of the People's Republic of China) (2014) JGJ106-2014: Technical specification for building pile testing. Building Industry Press, Beijing, China.

Nie RS and Leng WM (2013) The vertical load bearing behavior of single pile under the action of negative frictional resistance. Journal of Zhong Nan University (Natural Science Edition) 44(4): 1539-1544, https://doi.org/10.16285/j.rsm.2011.11.034 (in Chinese).

Takahashi K, Fukazawa N and Agiwara T (2004) Observational control of slurry shield tunnels with super close spacing under the nearby bridge abutments loads. Tunnelling and Underground Space Technology 19(4-5): 390, https://doi.org/10.1016/j.tust.2004.02.016.

Tong $\mathrm{MH}$ (1989) Application of underpinning technology in collapsible loess region. Industrial Building 19(3): 54-56, https://doi.org/10. 23204/j.gyjz198903014 (in Chinese).

Wu W (2016) Study on the bearing capacity variation behavior of pile foundation underpinning pile in saturated loess region. Journal of Lanzhou Jiaotong University 35(3): 29-33, https://doi.org/10.3969/j. issn.1001-4373.2016.03.006 (in Chinese).

Yamaguchi I, Yamazaki I and Kiritani Y (1998) Study of ground-tunnel interactions of four shield tunnels drive in close proximity, in relation to design and construction of parallel tunnels. Tunnelling and Underground Space Technology 13(3): 289-304, https://doi.org/10. 1016/S0886-7798(98)00063-7.

Yang XJ, Deng FH and Nie W (2006) Research on the influence of short distance Crossing Construction of Metro Tunnel on the bearing capacity of pile Foundation. Journal of Rock Mechanics and Engineering 25(6): 1290-1295, https://doi.org/10.3321/j.issn:10006915.2006.06.031 (in Chinese).

Zhu YP, Zhao TS and Chen CL (2013) Experimental study on the change of pile negative friction along pile length. Rock and Soil Mechanics 34(Supp 1): 265-273, https://doi.org/10.16285/j.rsm.2013.s1.078 (in Chinese).

\section{How can you contribute?}

To discuss this paper, please submit up to 500 words to the editor at journals@ice.org.uk. Your contribution will be forwarded to the author(s) for a reply and, if considered appropriate by the editorial board, it will be published as a discussion in a future issue of the journal. 